17 Iverson, G. M., Nature, 227, 273 (1970).

18 Mitchison, N. A., Eur. J. Immunol., 1, 65 (1971).

19 Taylor, R. B., and Iverson, G. M., Proc. Roy. Soc., B, 176, 393 (1971).

20 Iverson, G. M., in Cell Interactions (edit. by Silvestri, L. G.), 3 (North Holland Publ. Co., Amsterdam, 1971).

21 Janeway, C. R., and Paul, W. E., Eur. J. Immunol. (in the press).

22 Asherson, G. L., and Zembala, M., J. Exp. Med., 132, 1 (1970).

23 Raff, M. C., Transplant. Rev., 6, 52 (1971).

${ }^{24}$ Celada, F., Schmidt, D., and Strom, R., Immunology, 17, 189 (1969).

25 Rubin, B, Scand. J. Immunol., 1, 125 (1972).

26 Asherson, G. L., and Allwood, G. G., Immunology, 22, 493 (1972).

\section{Chimaeras and the Forbidden-clone Theory of Self-tolerance}

THE forbidden-clone theory of self-tolerance, which postulates that if immunologically competent cells capable of anti-self reaction arise they are soon eliminated, was widely accepted for a long time $e^{1-3}$, but it has recently been challenged ${ }^{4-6}$. Part of the challenge rests on the demonstration that a factor capable of blocking anti-self reaction is present in the serum, and part on in vitro studies indicating that cells capable of anti-self reaction occur in mice and rats. The studies with mice used chimaeras, also known as allophenic or tetraparental mice, which are made by fusing morulae of different genotypes. It is probably too early to say whether the forbidden-clone theory has been dethroned, but it may be pointed out that the studies with chimaeras are open to objection. As chimaeras may again be used for work of this nature, this objection is perhaps worth stating.

It is based on the fact that the two types of cells in a chimaera are not uniformly mixed throughout, and the mixture is generally far from intimate. Our examination of 10 chimaeras made from pigmented and unpigmented genotypes, all showing a good mixture of the two types of pigment cells in the fur, revealed that not only were large parts of the pigmentary layer of the retina of one kind or the other, but one retina was wholly pigmented, one almost wholly pigmented, and three almost wholly unpigmented ${ }^{7}$. The distribution of the migratory pigment cells in the iris, choroid and inner ear was similarly uneven ${ }^{8}$. To obtain a clearer picture, I examined the Harderian gland in the same animals. This is a large, thick structure, which almost surrounds the medial half of the eye, and is extremely rich in melanocytes. Two glands (in different animals) had no pigmented cells at all, and three had large parts that were entirely unpigmented. For obvious reasons it is impossible to say whether any gland was colonized solely by pigmented cells, but it is reasonable to assume that a comparable number might have been, the histological appearance of some being consistent with this assumption. Taking the entire cranial region, two chimaeras were unilaterally lacking in pigmented melanocytes of the migratory type, and one or two presumably in unpigmented ones.

If the chimaeras can be so wanting in uniformity in regard to pigment cells of both types, they may well have large regions in the thymus that are of single origin. An appreciable proportion of lymphocytes would then be expected to acquire their specificity in a region of their own genotype, and so be capable of reacting against cells of the other type. As the formation of lymphocytes is believed to be a continuous process, such cells would be found in the lymph nodes of chimaeras at all times, and their presence would not by itself rule out the mechanism implicit in the forbidden-clone theory as an additional factor in self-tolerance.

Department of Animal Genetics,

M. S. DEOL

University College London

Received February 1, 1973.
${ }^{1}$ Burnet, F. M., The Clonal Selection Theory of Acquired Immunity (Cambridge University Press, Cambridge, 1959).

2 Wilson, D. B., and Billingham, R. E., Adv. Immunol., 7, 189 (1967).

${ }^{3}$ Immunological Tolerance (edit. by Landy, M., and Braun, W.) (Academic Press, New York, 1969).

${ }^{4}$ Wegmann, T. G., Hellström, I., and Hellström, K. E., Proc. US Nat. Acad. Sci., 68, 1644 (1971).

5 Phillips, S. M., Martin, W. J., Shaw, A. R., and Wegmann, T. G., Nature, 234, 146 (1971).

6 Wekerle, H., Cohen, I. R., and Feldman, M., Nature New Biology, 241, 25 (1973).

7 Deol, M. S., and Whitten, W. K., Nature New Biology, 238, 159 (1972).

${ }^{8}$ Deol, M. S., and Whitten, W. K., Nature New Biology, 240, 277 (1972).

\section{Dislocations in Tobacco Mosaic Virus}

I Do not allege that the way Butler and Klug use "dislocation" is incorrect. I merely point out that as crystal dislocations occur in tobacco mosaic virus (TMV) and may perform important functions, "confusion is bound to arise if the term dislocation continues to be used loosely". Confusion is even more likely when the term is used in the same context by the same group in both strict ("screw dislocation"1) and loose (for example on p. 133 of ref. 2, "step dislocation at the end of the single helical rod") senses.

Butler and Klug deny my statement that members of their group refer to helical forms being dislocated or containing a dislocation. The second quotation above is sufficient to show their denial is false. I can supply a corroboratory quotation from every source I cite.

There is nothing wrong with taking the disk as the referenceI find a different reference more convenient. My reference is similar to Klug's radial projection ${ }^{3}$, which he and his coworkers use elsewhere but not here.

Just as Butler and Klug found it necessary or convenient to present detailed models "to give some general feel for the process", so have I. Without detailed models an explanation would be difficult if not impossible. What may appear to them "differences in detail" are in fact important differences: as I explain, one of their mechanisms converts the disk directly to a portion of a helix with the same number of subunits per turn as in the completed virion whereas the other requires an additional step.

My mechanisms, based on theirs, depend no more on "continuity of the disk" than do theirs. Just because subunits can be gained or lost in no way rules out dislocations. On the contrary, a very important mode of movement of dislocations requires the loss or gain of subunits ${ }^{4}$. It is similar to the mechanism of climb that I describe.

In their final paragraph Butler and Klug express an opinion which I am confident will be proved wrong. What can be stated with certainty is that dislocations are present in many types of biological structures. The bibliography on dislocations in biological structures which I am compiling already contains more than a hundred references.

Department of Chemical Engineering,

W. F. HARRIS

University of the Witwatersrand,

Johannesburg, South Africa

Received January 23, 1973.

${ }^{1}$ Butler, P. J. G., Nature, 233, 25 (1971).

2 Durham, A. C. H., thesis, University of Cambridge (1970).

${ }^{3}$ Klug, A., Crick, F. H. C., and Wyckoff, H. W., Acta Cryst., 11, 199 (1958).

${ }^{4}$ Harris, W. F., and Scriven, L. E., Nature, 228, 827 (1970). 